\title{
OS VÉUS DA ESCRITA AUTOBIOGRÁFICA EM JACQUES DERRIDA
}

Milena Magalhães

UNIR/RO

\section{RESUMO}

Este artigo objetiva fazer uma leitura de algumas figuras do livro Voiles, de Jacques Derrida. As referências à vida marcam toda a retórica desse texto, avizinhando-se do autobiográfico ao comentar um texto supostamente autobiográfico (no caso, a narrativa Un ver à soie, de Hélène Cixous, também contida no livro), acentuando a possibilidade e a impossibilidade desse registro. As cenas que remontam à “verdade” da existência trazem à tona paradoxalmente o limite ficcional que as atravessa. Essa aporia é marcada tanto pela concepção quanto pela dramatização de que em todo texto "existe um segredo”. Porém, como está tematizado em Paixões, o segredo não é de ordem fenomenológica, ou mesmo psicanalítica; não é um fenômeno que possa ser desvendado nem que possa ser desmistificado pelo outro.

\section{PALAVRAS-CHAVE}

Jacques Derrida, autobiografia, Voiles

\section{A QUESTÃO DA AUTOBIOGRAFIA COMO TAL}

Embora o primeiro livro do filósofo francês (ou franco-argelino, se quisermos realçar a sua dupla condição) Jacques Derrida tenha sido traduzido no Brasil ainda na década de 1970 e haja traduções periódicas de seus livros desde então, os seus livros mais recentes ainda são relativamente desconhecidos por aqui. Em muitos contextos acadêmicos, ele é tão somente o autor de A escritura e a diferença e de Gramatologia, dois livros que, por sua complexidade e sua relação tensa com algumas das heranças acadêmicas brasileiras (sendo o estruturalismo a mais evidente), foram pouco lidos, embora tenham sido discutidos por escritores da envergadura de Silviano Santiago e 
Haroldo de Campos; daí a razão por que pode parecer estranho relacionar seu nome à autobiografia.

A afirmação de que seu corpus é atravessado por traços autobiográficos, espalhados de maneiras diversas um pouco por toda parte, não é tranquila por pelo menos duas razões: primeiro, pela extensão de sua obra, que compreende mais de 60 volumes. Os livros em que os traços autobiográficos estão mais evidentes, exceção para Circonfissão e $O$ cartão postal, ainda não estão publicados no Brasil, o que, de certo modo, impede o acesso a eles. Seria, talvez, preciso pensar as políticas da tradução que priorizam determinado tipo de livro, aparentemente negligenciando aqueles em que a definição do gênero é mais problemática.

Nos livros que lançam questões à autobiografia, o interesse de Derrida pela literatura se explicita desde o modus operandis. Não se trata de afirmar que estes podem ser vistos como literatura, e sim que trazem na sua retórica traços normalmente relacionados ao fazer literário, sobretudo a desagregação da sintaxe, o desarranjo no conteúdo, a junção de fatores aparentemente contraditórios; tudo isso acrescenta uma dificuldade na identificação da pertença ao gênero. Livros como Glas, Voiles, La contre-allée, Mémoires d'aveugle reduzem a capacidade de conceituação, uma vez que demarcam não um estilo, mas uma negação mesma à noção de estilo, uma vez que perscrutam aquele ponto da língua em que esta deixa de servir à comunicação para investigar aquilo que o ensaísta francês Roland Barthes chamou de, entre aspas, "para além da linguagem”, considerando que a língua exige uma espécie de submissão às suas leis. É o próprio Barthes quem afirma: “Sabe-se que a língua é um corpo de prescrições

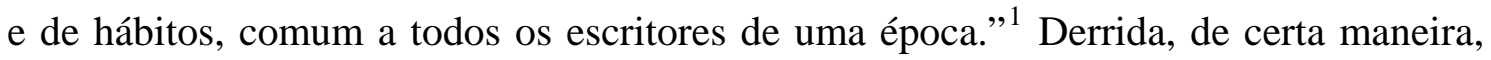
insurge-se contra essas prescrições quando, em Le monolinguisme de l'autre, em um simulacro de confronto entre dois pensamentos distintos que parecem habitar a mesma pessoa, afirma que tem apenas uma língua e esta não lhe pertence; ao que o seu outro aponta de imediato a "incoerência”, a “inconsistência” dessa afirmação. Ao reafirmar a sua condição através do seu alter ego, é deste lugar, deste território de “incoerência”, de “inconsistência”, sempre entre aspas, deste estar "à beira do francês, unicamente, nem nele nem fora dele”, que ele estabelece a sua relação com a língua, que é ao mesmo tempo de submissão e de insubmissão ao “corpo de prescrições e de hábitos” a que se refere Barthes. É no ato mesmo de sua estranha afirmação ("Sim, eu não tenho senão

\footnotetext{
${ }^{1}$ BARTHES. Lé degré zéro de l'écriture, p. 177. (Todas as traduções são minhas.)
} 
uma língua, ora ela não é minha”) que se indicia o seu duplo gesto. Mais além, ele vai afirmar: "Pois, confesso, eu me entrego sempre à língua.”2 Mas que língua é esta, que, como ele disse, não é o francês, mas um “à beira do francês”? O desejo, explicitado de modo quase messiânico, de fazer, ou de saber fazer, com que algo aconteça a esta língua se traduz em textos de difícil classificação, sempre margeando mais de um gênero.

De fato, existe uma tradição francesa de atenção ao modo de enunciação. Autores como Maurice Blanchot, Roland Barthes, Gilles Deleuze, cada um, à sua maneira, tratam da linguagem usando-a de maneira própria, assinando-a como uma prática. Por isso, nomeamo-los tão facilmente escritores. No entanto, ao contrário destes, quando Derrida assim o faz, não cria um efeito de aproximação, e sim de recuo, de distanciamento e mesmo de negação, o que está em consonância com a sua semântica da paixão. O que ele aponta é uma relação direta, um tête-à-tête, com a língua que tenta desmontar todas as leis inerentes a ela, restando-lhe tão somente "uma lei da língua” que só pertenceria a ele. Ora, isso significa colocá-lo de imediato fora da lei, o que é modalizado por ele a partir do constante uso do "como se”, que ganha um estatuto não apenas de hipótese, mas também de dúvida: “Como se eu tentasse desempenhar este papel, o de me identificar com este herói-mártir-pioneiro-legislador-fora-da-lei...”. 3

Os sentidos do autobiográfico estão enxertados nessa língua por vezes ambígua, complexa; efeito de um trabalho que renega a improvisação, o apenas "falar-a-respeitode” determinado assunto sem demonstrar o que há nele de complicado, o que nele exige atenção, minúcia, exasperação. Esta é a segunda razão por que é difícil afirmar que o traço autobiográfico está um pouco por toda parte, pois este alastramento não constitui uma exemplaridade, um modelo, uma vez que são lançados (embora não de forma aleatória) em textos com uma estrutura discursiva não-convencional. Ele cola a experiência da vida nos seus escritos, tornando-os autobiográficos e ao mesmo tempo filosóficos. A essa fusão, essa confusão, se juntam aspectos que dramatizam os dois gêneros, produzindo ruídos em um e outro. Os sentidos não estão apenas na semântica, mas também na sintaxe, que não chega a ser desordenada, mas impõe um estranhamento na ordem direta das frases, que quase sempre são geridas por um uso particular de vírgulas, por uma atenção à terminologia das palavras, pelos jogos de sentidos de uma palavra, etc. Em Derrida, desde a relação com os títulos, que podem ou não

\footnotetext{
${ }^{2}$ DERRIDA. Le monolinguisme de l'autre, p. 80.

${ }^{3}$ DERRIDA. Donner la mort, p. 79.
} 
corresponder ao assunto tratado no texto, a forma do dito interessa tanto quanto o dito; força um alargamento no conceito, não em busca de um outro, mas, sim, para mostrar as possibilidades e também os seus limites.

Com seus traços autobiográficos lançados em lugares inesperados, Derrida faz lembrar que a representação das coisas, inclusive a da vida, só pode gerar simulacros; são fantasmas, espectros que se dispõem ao longo das páginas. Tudo pode ser combinado de modo original, obedecendo a outra lei. Sendo assim, a relação com a lei demanda uma ética da alteridade, muito mais do que uma estética, embora se saiba que reivindicar uma alteridade não significa impingir uma demanda de singularidade, uma vez que esta é sempre interrompida pela lei do outro. O que se reivindica, como já dito, é um lugar à margem - a mesma margem que atravessa o seu modo de leitura, pois o que ele faz não é mais do que ler as margens de textos que lhe chamam a atenção, fazendo-o através da sua língua, que está “à beira do francês”.

Não é de outro modo com a autobiografia. Não importando qual seja o olhar lançado sobre esta palavra, sabemos de antemão que, desde a sua formação, cada uma das suas partes pode ser desmembrada: auto-bio-grafia, sendo que cada uma pode ocasionar discussões infinitas sem chegar a um consenso. Como o Visconde partido ao meio, do escritor Italo Calvino, esta palavra traz em si a possibilidade de ser mutilada, estraçalhada, e ainda assim sobrar partes dela que lhe permitem uma existência, uma afirmação, um ter lugar.

O registro autobiográfico entra em processo de rasura, deixando aparecer as brechas do discurso nas quais se escondem os meandros com que se chegam às “posições”, aos pontos de vista. Não se trata de aderir ao gênero. Faz-se, antes, uma “certa modulação”, uma “certa transformação”. Duas modalizações são feitas: tanto no discurso teórico-filosófico quanto no autobiográfico. Se por um lado ele afirma haver uma lei do gênero; por outro se recusa a segui-la; inscrevendo-se no gênero para contrariá-lo, para inserir um traço de desestabilização. No entanto, uma contrariedade que não deseja ser exemplar, que quer ter lugar ali e apenas uma vez. E ter lugar por razões específicas, determinadas, que não se repetem no movimento dos textos. O traço autobiográfico existe um pouco por toda parte, mas, através da cena retórica, se comporta como se não existisse um programa que mediasse o seu aparecimento. Nesse sentido, não se cria nenhuma teoria da autobiografia, que deveria ficar ao lado de - ou em contraposição a outras. 


\section{A QUESTÃO DE VOILES}

Se traços autobiográficos se espalham em todo o corpus de Jacques Derrida, vimos que estes carregam muitos questionamentos para além das questões das escritas de si. A própria semântica de “traços” sofre interferências no corpus deste filósofo, de modo que o traço faz surgir de modo espectral o que se perdeu. A cada vez que há a promessa do aparecimento do corpo em um corpus, em forma de narração de fatos relativos à vida, a origem se perde. Como em Hamlet, a verdade é proferida por um fantasma, daí vivenciarmos ao mesmo tempo a verdade e o seu luto. Indistintamente, podemos afirmar estes traços como lances que não cedem à durabilidade do acontecimento. O fato vivido não chega a ser acontecimento; é o que acontece em um instante e, no momento da transposição para o escrito, cede a outra envergadura de sentido. Utilizando-se da semântica dos véus, o que haveria não seria um desvelamento, e sim uma re-velação, no sentido de velar de novo, e ainda por muito tempo, o segredo que se diz segredo apenas para se autovelar.

No livro Voiles, os princípios de semelhança e dessemelhança com a autobiografia propriamente dita, impostos por Derrida, traduzem a maneira como os traços autobiográficos em sua obra são dispostos. Neste, temos dois textos, um de Hélène Cixous, intitulado Savoir, e o de Derrida intitulado Un ver à soie. Um bicho da seda. A promessa do livro, desde a folha "fora do livro", na prière d'inserer, é o de ser, ou de estar, em todos os gêneros. É esta a questão. E a questão do gênero é tanto a das diferenças sexuais quanto a das diferenças na escrita. Portanto, não cabe fazer de Un ver à soie, o texto de Derrida, um exemplar dentro da totalidade do seu corpus. Não se trata de isolá-lo, mas, sim, de perscrutar o que aí faz parte do “programa Derrida” e ao mesmo tempo funciona como excedente deste programa. E quando fazemos alusão ao “programa Derrida”, inevitavelmente nos remetemos a outro texto essencial da questão autobiográfica neste autor, que é Circonfissão.

Quanto a Un ver à soie, este faz parte da grande narrativa confessional que se alastra no corpus deste filósofo e, assim sendo, é ao mesmo tempo uma adesão e uma traição ao registro autobiográfico como tal. Esta expressão, como tal, utilizada pelo filósofo Jean-Luc Nancy para se referir a Derrida, é aquela que não deve ser alcançada, é aquela que é traída por ele a cada vez que se aproxima do gênero, inserindo neste sempre um transtorno. Como consentir um ver a si, uma verdade de si, uma veracidade? Como tratar a verdade? 
Uma das formas é queimar - e não apagar - a consistência do eu, proferindo uma frase paradoxal e cifrada como "Eu a cinza”. No fim do livro La dissémination, depois do fim, como uma nota de rodapé, mas sendo uma dedicatória, há uma sentença, ligada à questão do segredo e da partilha, que põe um ponto final, enfim, no livro. Eis a sentença: “il y a là cendre”. Ela será comentada, muitos anos depois, no pequeno livro intitulado Feu la cendre. E também em outros textos, como O cartão postal e Glas. Há cinza, fogo cinza, eu cinza; as substituições que acompanham a cinza são maneiras de falar "em segredo" de algo que permanecerá em segredo, mesmo que um livro seja dedicado ao assunto, pois os sentidos se deslocam. Um vocabulário enorme - que adquire neste filósofo um aspecto idiomático - ganha corpo em torno do "problema” da verdade (lance, cena, segredo, resto, cinza), sendo difícil arriscar definições em torno dessas palavras. Elas funcionam melhor em seus contextos, mas trazem em si parentescos, aproximações, ressonâncias que ajudam a compor o sentido de autobiografia, rasurando a prescrição da verdade presente na tradição filosófica.

No mesmo instante em que parece surgir um conceito, dispor sobre ele, é como se fosse preciso deixar claro que isso não basta. O sentido do eu como cinza, de um eu que não basta para constituir um gênero, acompanha todo o discurso de Derrida em Voiles, compondo uma estrutura que encena uma espécie de "errância” dos gêneros, embora em sua estrutura primeira se assemelhe a um diário de viagem. Dividido em três partes, que teriam sido escritas em datas e em lugares diferentes (em direção a Buenos Aires, o que sugere ter sido escrito no avião, em Santiago do Chile e Valparaíso, e em São Paulo), cada um dos deslocamentos é marcado por uma “mudança” de voz, indicando, entre outras consequências, que a travessia do corpo influencia a tessitura da escrita. $\mathrm{O}$ fato de os textos registrarem a data e o lugar marca a singularidade do momento e do lugar onde foram escritos. O que é escrito não se repetirá em outro lugar nem em outra data, ${ }^{4}$ e isso é realçado pela mudança de tom a cada vez que mudam as datas e os lugares. Desde a primeira parte a tessitura como uma sucessão de fios que formam um tecido é rasurada. No caso, trata-se de “desfiar um tecido” ou, antes, "velar a sua diminuição”, remetendo-se também à tessitura da voz, à adequação da escala para um tom menor. Como predito por uma das vozes, o léxico musical posto em cena serve para dar sentido ao texto que, querendo baixar o som, diminuir os intervalos, o faz na intenção de fazer “ouvir mais”. O confronto de diálogos da primeira parte, em que vozes

\footnotetext{
${ }^{4}$ Cf. DERRIDA. Feu la cendre.
} 
duelam as suas proposições, enfatiza as tensões que ocorrem quando se quer determinar inicialmente a intenção, trazendo à tona o engodo da ideia de que uma intenção pode ser colocada como princípio para a construção de um texto.

Na primeira cena autobiográfica, Derrida conta que, quando pequeno, ouvia as mulheres da família, ao tricotarem malhas de lã, dizerem que era preciso diminuir os fios. Embora seja uma rápida passagem do primeiro parágrafo, temos aqui o fio organizador da retórica do texto, que é construído com um entrançamento de assuntos à maneira das mulheres de sua infância que, para diminuírem o fio, tricotavam duas malhas ao mesmo tempo - "representar mais de uma em todo caso". ${ }^{5}$ Essa lembrança que tanto impressiona Derrida faz com que de fato seja ilegítimo falar em fio condutor, pois o seu texto quebra a cada vez a expectativa, não tendo um seguimento evidente. Três cenas são representadas - ou mais de três. A cena íntima marca a retórica de todas as cenas.

A segunda recordação de infância tem um caráter distinto. Encerrando a última parte do seu texto, Derrida dobra ou desdobra o gesto de Cixous. Conta também uma história, um segredo como que endereçado à escritora, que havia narrado um em Savoir, ao revelar a operação a que foi submetida na infância para se livrar da miopia - um segredo que ele afirma desconhecer até então, apesar dos mais de trinta anos de amizade. Marcando tipograficamente a sua narrativa, utilizando caracteres em itálico, Derrida conta uma “verdadeira recordação da infância”: a sua criação de bicho-da-seda. Por outro lado, a "verdadeira recordação da infância", quando narrada, já não tem o mesmo caráter da narrativa de Cixous. A generalidade da estrutura da autobiografia, se existe, é o contraponto do discurso de Un ver à soie. Devido a isso, o segredo não faz parte da metáfora posta em ação pelo desvelar, revelar, esconder, dos “véus”. O que se empreende em Voiles não é uma busca pela verdade do texto de Cixous nem pela verdade da vida de Derrida. O segredo a que este alude não é uma "metáfora da verdade”, tampouco a "metáfora da metáfora”, a "verdade da verdade” ou a "verdade da metáfora” nas quais se confunde a semântica do véu.

É a própria forma do segredo, do desvendamento impossível do segredo, que é tocada, daí a injunção de que é preciso renunciar ao toque. Como afirma Michaud, em Derrida, a questão do segredo carrega uma aporia: o segredo está destinado a permanecer em segredo. É algo impossível de ser contado, revelado, porque não estaria

\footnotetext{
${ }^{5}$ DERRIDA. Voiles, p. 25.
} 
escondido, guardado; seria uma questão para além da carga semântica já existente do segredo. Nas palavras da autora:

Todo interesse do trabalho de Derrida no seminário consagrado a esta questão foi precisamente de colocar em dia uma outra possibilidade do segredo, que não seria mais somente da ordem do que é escondido ou do que não se mostra, permanecendo invisível, imperceptível, intangível, oculto, resumindo in-acessível, um segredo definido em termos de negatividade, mas um segredo que, "antes mesmo de ser modalizado, especificado, explicado em sua origem ou em sua gênese" (S, I, 1), não se referiria simplesmente à ordem do dizer e da linguagem. ${ }^{6}$

Esse segredo antes do discurso, desprovido de negatividade, seria um segredo que não se diz, mas poderia ser dito. Não seria retraimento, subtração de algo, vindo do sentido latino do termo secretus. Levando ao limite o sentido de segredo por meio de inúmeras referências, Derrida, em Donner la mort, ${ }^{7}$ ao reconhecer na expressão "ver o segredo" uma citação do Evangelho de Mateus, aponta que "a penetração do segredo, neste, é confiada ao olhar, à visão, à observação - em detrimento da escuta, do faro ou do tato". ${ }^{8}$ E, no entanto, o segredo pode escapar do campo da visão. Ele pode ser visto e continuar um segredo, sendo acessível através de outros sentidos. Existem diferentes modos de invisibilidade (“A voz não é invisível como a pele sob uma vestimenta”). ${ }^{9}$ A cripta grega, diferentemente do secretum latim, abre a possibilidade de retirar o segredo do invisível, do escondido. O cifrado, codificado, não está necessariamente invisível. Ele dá o exemplo da escrita, por exemplo, uma carta em chinês ou em hebraico, embora visível, não é acessível a todo mundo. O sentido da cripta propicia a abertura do segredo para além do não visível, em direção ao ilegível e ao indecifrável.

Embora pareça privilegiar o segredo filiado ao sentido de cripta grega, o que este autor busca é outra direção, que esteja no intervalo de um e de outro e possibilite romper com as oposições aparentes entre íntimo e estranho; público e privado. A tentativa, segundo Michaud, é de manter-se afastado do que é declaradamente sua herança. E ele não cessará de fazê-lo mediante o desfazimento das oposições aparentes. Quando Derrida afirma que dissimula, “mas não da mesma maneira”, encontramos eco

\footnotetext{
${ }^{6}$ MICHAUD. Tenir au secret (Derrida, Blanchot), p. 16.

${ }^{7}$ Em 1991, Derrida ofereceu um seminário na École des Hautes Études en Sciences Sociales, intitulado "Répondre du secret", que foi largamente utilizado nesse livro.

${ }^{8}$ DERRIDA. Donner la mort, p. 122.

${ }^{9}$ DERRIDA. Donner la mort, p. 124.
} 
da paixão pelo segredo. O desfazimento das oposições se dá por meio de cenas cifradas, que pedem quase sempre uma leitura que considere a dupla lógica de cada texto. Por isso, a sua escrita remete-se a ela mesma, em uma aproximação com o texto ficcional, sem de fato jamais sê-lo. Dessas incursões, talvez a narração da sua criação do bichoda-seda seja a mais importante.

\section{A FIGURA DO BICHO-DA-SEDA}

Ceder à exposição de si requer, antes, um a-fora impossível da estrutura; a tentativa de "diminuir" os fios dos sentidos da exposição. E isso só é possível na exposição, não de si, mas da impossibilidade de revelação do ente. Daí advém a dívida com o bicho-da-seda. Essa figura explica o que parece um aporia intransponível, a que reside na constatação de que Derrida, ao mesmo tempo em que se inscreve com o eu, nega veementemente o desvelamento do eu. A presença solicitada estaria no intervalo do velamento-desvelamento típico da metamorfose do bicho-da-seda. Derrida confirma a importância do bicho-da-seda, mostrando como este não é uma figura entre outras:

Ele [o bicho-da-seda] enrola nele toda a história de minhas explicações com a verdade, a revelação, o desvelamento, o véu, a teia, o tecido, o têxtil do talit animal que se toca ... O que me interessa aqui é que o animal nomeado bicho-da-seda produz vegetal. Depois de ter comido - intimado, na verdade - suas folhas de amoreira, de vegetal, o vegetariano se fecha, certo, ele se intima, mas ele se intima no que a natureza lhe ordena tirar de si, de produzir fora se separando dele e ao mesmo tempo se enterrando nele, o casulo, de secretar em si fora de si, d'extimar ... exteriorizar o que ele é e que vem dele, que ele guarda ou que lhe guarda perdendo-o: a seda como si-mesmo. Aparentemente ex nihilo. ${ }^{10}$

A passagem do bicho-da-seda, que lhe é imposta de fora, pela natureza, acontece, no entanto, nele mesmo, ficando invisível ao outro; assim como a "verdade" em um texto, mesmo quando é proclamada, programada, se faz nela mesma, sendo impossível identificá-la como tal. Como ele sugere, diante desse trabalho, vemos o progresso da tecedura, mas de fato nada se vê. A criança - que ele continua sendo cuidava e alimentava várias vezes ao dia o bicho-da-seda. Antes mesmo de ter posto o talit, é a sua primeira experiência do segredo. Impossibilitado de distinguir o sexo do bicho-da-seda, restando para ver um esperma muito fino, como um "milagre" de

\footnotetext{
${ }^{10}$ DERRIDA. La connaissance des textes. Lecture d'un manuscrit illisible (avec Simon Hantaï e
} Jean Luc Nancy), p. 150-151. 
ejaculação feminina, ele o alimentava como se quisesse "surpreender o segredo de um prodígio”, “o segredo além do segredo”. Para Derrida, não houve apropriação do segredo. O que ele se apropriou sem deixar em si, de fora, ao longe, foi a operação da secreção; o secretar da secreção. Secreção, secretar, secreto, segredo. O que pode ser observado é o progresso do segredo; como o bicho-da-seda secreta a secreção fora dele, diante dele, o que, entretanto, não o abandonaria mais, que lhe pertencia, que se transformaria no que era próprio dele, (“uma coisa que não era uma coisa, uma coisa que lhe pertencia e retornava a ele como próprio”). ${ }^{11}$ Em uma das passagens mais reveladoras da recordação de infância, o narrador confessa o que foi e continua sendo para ele a cultura do bicho-da-seda:

Esta filosofia da natureza era para ele, para a criança que eu era, mas que ainda continuo sendo, a própria ingenuidade, sem dúvida, mas também o tempo da aprendizagem infinita, a cultura da confecção, a cultura confeccionada segundo a ficção, a autobiografia do logro, Dichtung und Wahrheit, um romance de formação, um romance da sericicultura que ele começava a escrever com a intenção de se endereçar a ele mesmo. ${ }^{12}$

A “autobiografia do logro" é, portanto, o que encena uma "aprendizagem infinita” da cultura de si-mesmo. Porém, um si-mesmo que se prepara para esconder a si-mesmo, que ama fazê-lo. Como o bicho-da-seda, "preparar-se para se esconder, a si mesmo, amar se esconder, com a intenção de se produzir no exterior...”. ${ }^{13}$ Toda essa operação é a do segredo além do segredo, que joga com todos os sentidos do visível: o invisível como visível guardado, o visível cifrado, ou o não visível como outro além do visível. ${ }^{14} \mathrm{O}$ desmembramento da estrutura autobiográfica, tendo começado bem antes, não é visível ao leitor, a exemplo do trabalho do bicho-da-seda. A confissão é, assim, uma confissão com os sentidos do invisível e de como estes são indissociáveis na “cultura da sericicultura”, o outro nome para a autobiografia. O que se sugere é que pouco importa se uma confissão é ficcional ou não, uma vez que pertence ao espaço do segredo; isto é, à literatura, pois, se assim pertence, serve para desmistificar o conceito de verdade. Passar pelo processo da sericicultura - da autobiografia - é atravessar algo que lhe pertence e que retorna a ele. O relato da infância é justamente para dizer da

\footnotetext{
${ }^{11}$ DERRIDA, Voiles, p. 83.

${ }^{12}$ DERRIDA. Voiles, p. 84.

${ }^{13}$ DERRIDA. Voiles, p. 83.

${ }^{14}$ Cf. DERRIDA. Donner la mort.
} 
impossibilidade de fazer relatos. A narrativa que é prometida, anunciada desde a primeira parte, é por fim um relato sobre aquilo que não se vê, em que se tem que crer sem ver. O corpo do bicho-da-seda, quanto mais se transforma em obra, na sua obra, mais se esconde de si mesmo, o que significa adquirir a sua posse, a sua propriedade, o que é uma potente figura para a obra derridiana. Eis o bicho-da-seda envolto na sua “noite branca” para retornar a si mesmo, em um retorno que é também a sua morte. Cumpre-se a promessa de uma das vozes de tudo contar, de não deixar nada intacto, mas o que se tem a contar é também um segredo. O perjúrio que seria esclarecer a obra é ainda uma vez adiado.

A cena confessional é frustrada, é uma mistura de verdade e ficção impossível de distinguir onde começa uma e termina outra, de modo que, se atentarmos que "a ficção manifesta a verdade", ${ }^{15}$ podemos deduzir que a cena representada em Voiles guarda estreita relação com a ficção no momento mesmo em que promete dizer a verdade. Nesse caso, dizer a verdade é ocupar o lugar da ficção. No entanto, a escrita não está no espaço da literatura, assim como também não se põe no espaço da filosofia; é no movimento entre uma e outra que se localiza o registro autobiográfico.

\begin{abstract}
This article reads some figures of the book Voiles, by Jacques Derrida. Life references mark the rhetoricity of this text, drawing it closer to an autobiography by commenting on a supposedly autobiographical text (in our case, Un ver à soie, by Hélène Cixous, a narrative also inserted in the book), and by accentuating the possibility and impossibility of such register. The scenes that are redrawn to the "truth" of existence bring forth, paradoxically, the fictional limit that transfixes them. This aporia is marked both by the conceptualization and dramatization that in every text, "there exists a secret”. However, as it is thematized in Passions, the secret does not belong to the order of phenomenology, or even to the order of psychoanalysis; it is not a phenomenon that can be unveiled or that can be devitalized by the other.
\end{abstract}

\title{
KEYWORDS
}

Jacques Derrida, autobiography, Voiles

\footnotetext{
${ }^{15}$ DERRIDA. Glas, p. 495.
} 


\section{REFERÊNCIAS}

BARTHES, Roland. Lé degré zéro de l'écriture. In: . Euvres complètes. Livres, textes, entretiens. Paris: Seuil, 2002. t. I.

DERRIDA, Jacques. Glas. Paris: Galilée, 1974.

DERRIDA, Jacques. Feu la cendre. Cio che resta del fuoco. Paris: Éditions des Femmes, 1987.

DERRIDA, Jacques. Mémoires d'aveugle. L'autoportrait et autres ruines. Paris: Réunion des Musées Nationaux, 1990.

DERRIDA, Jacques. Le monolinguisme de l'autre. Paris: Galilée, 1996.

DERRIDA, Jacques. Voiles (avec Hélene Cixous). Paris: Galilée, 1998.

DERRIDA, Jacques. La contre-allée (avec Catherine Malabou). Paris: La Quinzaine Littéraire/Louis Vuitton, 1999a.

DERRIDA, Jacques. Donner la mort. Paris: Galilée, 1999b.

DERRIDA, Jacques. La connaissance des textes. Lecture d'un manuscrit illisible (avec Simon Hantaï e Jean Luc Nancy). Paris: Galilée, 2001.

MICHAUD, Ginette. Tenir au secret (Derrida, Blanchot). Paris: Galilée, 2006. 